\title{
The Fertility Trends among Married Finnish Women Born 1932-58
}

\author{
FJALAR FINNÄS
}

Institute of Social Research

Ảbo Akademi

\section{Introduction}

In the mid-seventies several large fertility surveys were carried out all around the world. In Finland a total of 5447 married women aged 18-44 years were interviewed in 1977 about their childbearing histories and a great number of background variables. The main purposes of the Finnish study were to obtain a detailed picture of the fast fertility decline and to find out what factors affect the fertility behavior in different segments of the population.

For various reasons the Finnish survey data have not been analyzed in a way that makes comparisons with the corresponding surveys in the Scandinavian countries possible. To remedy this lack to some extent I have now studied the data using the same methodology as was used when analyzing the Danish and Swedish data (Finnäs and Hoem, 1979 and 1980, and the reports from SUDA). To study the effect of the traditional demographic factors such as year of birth, age and length of previous birth interval I have used life table methods, but to account for other background variables I have fitted multiplicative hazard models for the birth intensities.

The main report is written in Swedish, and here I shall give a brief summary of the study and the main findings. As background I shall begin by describing the general fertility trends in Finland and mention some of the results from the Scandinavian countries. In addition to the sample surveys, in Sweden and Norway register data concerning all women have been analyzed as well (Johansson and Finnäs, 1983, and Brunborg and Kravdal, 1986).

\section{Background}

The post-war »baby-boom» was much more pronounced in Finland than in the other Nordic countries. The peak was reached in 1947 with a total fertility rate (TFR) of 3.47. Because of the high level the succeeding decline was fast, and in the midsixties fertility in Finland was at about the same level as in Sweden and Denmark, i.e. a TFR of some 2.5. After that the decline was equally strong in these countries for a few years, but in Finland it continued until 1973 when the TFR reached its minimum (1.49) so far. The slight increase that followed equalized the levels again in the late seventies. At that time the fertility in Norway was also about the same, but the way it had developed up to then had been rather different. In Norway the TFR rose from the beginning of the 50 s until the mid- 60 s reaching a level of almost 3.0. However, some ten years later it had fallen to 1.7 (Figure 1).

Using the published official statistics it is possible to show the more or less trivial result that the mean number of children per woman with children has decreased, since 
$\mathrm{Fi} \mathrm{g} \mathrm{u} \mathrm{r} \mathrm{e} \mathrm{1.} \mathrm{The} \mathrm{total} \mathrm{fertility} \mathrm{rate} \mathrm{in} \mathrm{Finland} \mathrm{and} \mathrm{the} \mathrm{Scandinavian} \mathrm{countries} \mathrm{in}$ 1945-1978.

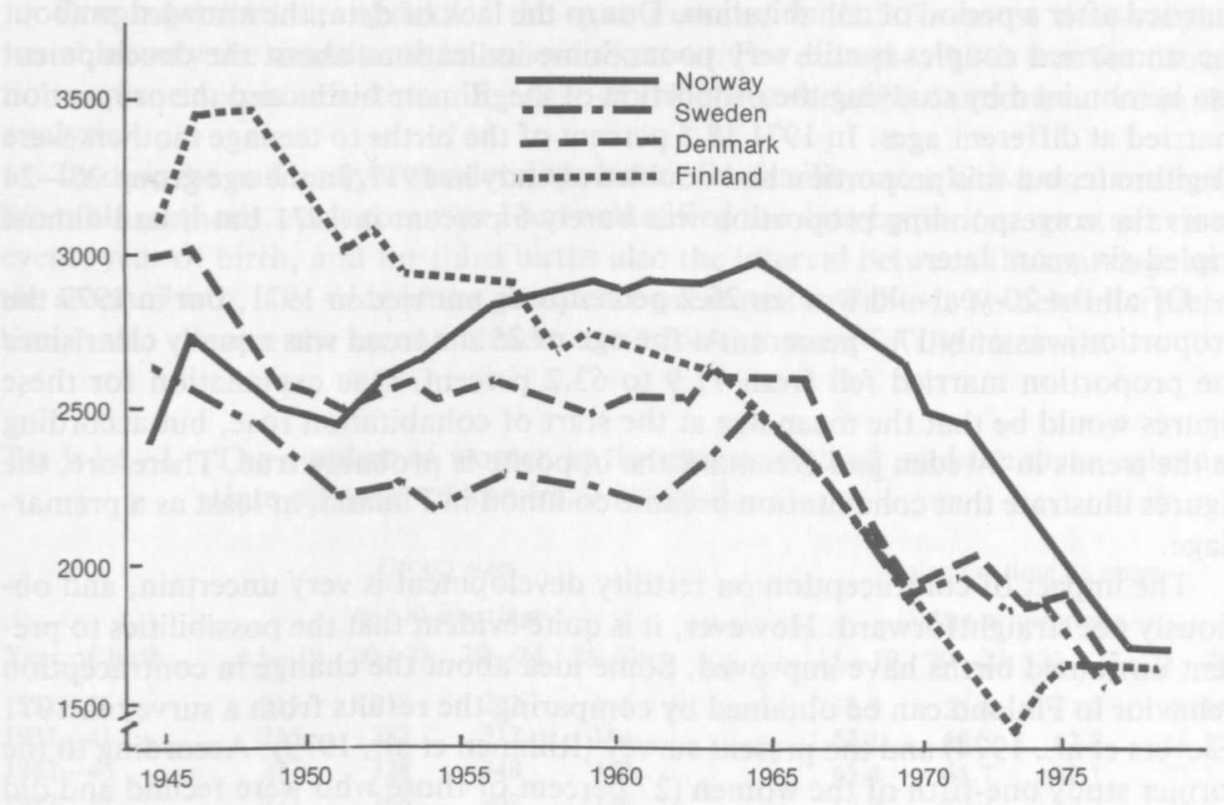

births of parity three and higher have become rather rare. In 1961 some 38 percent of the children born in Finland had a parity number higher than two, but in 1973 the corresponding proportion was just below 15 percent. Another related result is that the fertility among females over 35 years has fallen dramatically. In 1973 the age-specific fertility rate for the age group 35-39 years was only one-third of the corresponding rate in 1961.

The ordinary official statistics can illustrate the main trends of fertility development, but more detailed studies cannot be carried out. In spite of the figures mentioned above, it is impossible to really study development by parity, which is of great importance for the understanding of the great changes that have appeared. According to the studies in the Scandinavian countries the childless proportion remained almost unchanged until the cohorts born in the $50 \mathrm{~s}$. The same was true for second births, and the decline has been very small so far. In Sweden there was even a slight increase in the youngest cohorts among married women. In these countries the overall fertility decline is mostly due to the decline for higher parities.

Among cohabiting (unmarried or married) Danish women who had their first child before the age of 25 years, there were no systematic differences in the proportion having a second child, but in general teenage mothers had a shorter interval between births. The women that were over 25 years old at first birth had considerably lower birth intensities for a second birth. As for the higher parities the parity progression probabilities decrease by an increasing age at previous birth. However, it is important to take the previous behavior into account, since short birth intervals are connected with a higher propensity for further births.

During the period of fertility decline, there have been considerable changes in two connected fields of great importance for fertility, namely cohabitation and contraception. In Sweden and Denmark cohabitation without formal marriage started in the late $60 \mathrm{~s}$, and it has become a common and accepted way of living. This 
phenomenon came to Finland a little later, and it has not become equally common, at least not as a permanent cohabitation form. In Finland most couples seem to have married after a period of cohabitation. Due to the lack of data, the knowledge about the unmarried couples is still very poor. Some indications about the development can be obtained by studying the proportion of illegitimate births and the proportion married at different ages. In 197118.5 percent of the births to teenage mothers were illegitimate, but this proportion had doubled already in 1977. In the age group 20-24 years the corresponding proportion was barely 6 percent in 1971 but it had almost tripled six years later.

Of all the 20-year-old women 26.2 percent was married in 1971, but in 1977 the proportion was only 17.7 percent. At the age of 25 the trend was equally clear since the proportion married fell from 71.9 to 63.2 percent. One explanation for these figures would be that the mean age at the start of cohabitation rose, but according to the trends in Sweden and Denmark the opposite is probably true. Therefore, the figures illustrate that cohabitation became common in Finland, at least as a premarriage.

The impact of contraception on fertility development is very uncertain, and obviously not straightforward. However, it is quite evident that the possibilities to prevent unwanted births have improved. Some idea about the change in contraception behavior in Finland can be obtained by comparing the results from a survey in 1971 (Sievers et al., 1974) and the present survey (Riihinen et al., 1979). According to the former study one-fifth of the women (27 percent of those who were fecund and did not want to get pregnant) used the pill and 3 percent an IUD, but almost one-sixth used no method other than withdrawal. In 1977 the proportion using the pill had decreased in favor of the IUD, the proportions were a good tenth and a good fourth, and withdrawal had almost disappeared. In both surveys about one-third reported the condom to be the contraceptive device they used. The questions asked were not quite identical, but it is obvious that there was a develpoment towards more certain methods. Further, the new methods seem to have been more accepted among the younger women.

\section{Data and methods}

A random sample of 6,200 women aged 18-44 years on January 30, 1977 was picked out from the Central Population Register.The target population was women in their first marriage, and a total of 161 women in the sample were eliminated mainly due to marital dissolutions. For 38 of the rest the addresses could not be found, and the total number to be interviewed was therefore 6,001 . The interviews were carried out in the period from March to May 1977, and 90.6 percent of the women were reached and agreed to take part in the investigation.

The questionnaire was very extensive, but only a few of the questions are suitable for the methods used here. The observation plan, restricted to first-married women, suffers from several severe shortcomings. No information about informal cohabitation is available, and the effect of marital dissolutions and remarriages cannot be studied. The elimination of previously married women will probably lead to an overestimation of fertility in the older cohorts, since the women who get divorced generally have fewer children.

As cohabitation without formal marriage became more common in Sweden there was evidently some form of selection process involved, and as a consequence marital fertility rose although the general trend was downwards. The same can be expected 
to be true in Finland too, and the fertility for the youngest cohorts will probably be somewhat overestimated.

One important drawback of the questionnaire is that for most time-varying variables only the situation at interview is known. For example, this is true for education and socioeconomic status. Because of this these variables cannot be used in the analysis.

To describe and analyze the development of the fertility rates I have used ordinary life table methods. As is common I have classified the data by parity, age at previous event, year of birth, and for third births also the interval between the marriage and the second birth. The sizes of the groups are presented in Table I. To help interpretation I also present the mean calendar time for the onset of the intervals.

T a b l e I. The number of women in the groups studied, and the mean calendar time at onset of the birth interval.

\section{Group sizes}

Age at marriage

Year of birth $\quad 15-19 \quad 20-21 \quad 22-24 \quad 25-29$

$\begin{array}{ccccc}1932-36 & 215 & 218 & 242 & 191 \\ 1937-41 & 235 & 282 & 317 & 184 \\ 1942-46 & 277 & 328 & 348 & 212 \\ 1947-51 & 373 & 366 & 407 & 166 \\ 1952-58 & 330 & 235 & 115 & \ldots\end{array}$

Calendar time at onset

Age at marriage

$\begin{array}{cccc}15-19 & 20-21 & 22-24 & 25-29 \\ 52.9 & 55.6 & 57.9 & 61.3^{*} \\ 58.1 & 60.7 & 62.8 & 66.3 \\ 63.4 & 65.7 & 68.1 & 71.7 \\ 67.9 & 70.4 & 72.7 & 74.9 \\ 73.6 & 74.8 & 76.0 & \ldots\end{array}$

Age at the birth of the first child

$\begin{array}{cccccccccc} & 15-19 & 20-21 & 22-24 & 25-29 & 15-19 & 20-21 & 22-24 & 25-29 \\ 1932-36 & 126 & 186 & 253 & 219 & 53.7 & 55.5 & 58.0 & 61.5 \\ 1937-41 & 130 & 223 & 315 & 272 & 58.5 & 60.7 & 62.9 & 65.5 \\ 1942-46 & 160 & 235 & 313 & 330 & 63.5 & 65.8 & 68.0 & 72.0 \\ 1947-51 & 210 & 266 & 351 & 304 & 68.1 & 70.5 & 72.8 & 75.4 \\ 1952-58 & 179 & 171 & 118 & \ldots & 73.7 & 75.1 & 76.2 & \ldots\end{array}$

Age at the birth of the second child

$\begin{array}{cccccc}15-24 & 25-29 & 30-34 & 15-24 & 25-29 & 30-34 \\ 293 & 292 & 129 & 57.2 & 61.7 & 66.4 \\ 335 & 319 & 135 & 62.3 & 66.7 & 71.6 \\ 309 & 314 & 132 & 67.1 & 72.2 & 75.7 \\ 338 & 249 & \ldots & 72.0 & 75.6 & . . \\ 122 & \ldots & \ldots & 75.6 & \ldots & \ldots\end{array}$

Women born $1932-39$

Age at marriage

Interval between marriage and second birth (years)

$\begin{array}{lrrrrrrr} & 0-2 & 3-4 & 5-9 & 0-2 & 3-4 & 5-9 \\ 15-20 & 204 & 151 & 95 & 57.3 & 59.5 & 62.5 \\ 21-23 & 146 & 127 & 105 & 60.7 & 62.5 & 65.2 \\ 24-29 & 100 & 118 & 78 & 63.9 & 66.1 & 68.6\end{array}$

Women born $1940-46$

$\begin{array}{lrrrrrrr}\text { Age at marriage } & 0-2 & 3-4 & 5-9 & 0-2 & 3-4 & 5-9 \\ 15-20 & 175 & 148 & 119 & 64.8 & 66.8 & 69.9 \\ 21-23 & 101 & 138 & 143 & 67.7 & 69.7 & 73.1 \\ 24-29 & 33 & .91 & 72 & 72.0 & 73.5 & 74.9\end{array}$

$* 61.3=1961.3$ 
In all the groups I have estimated the occurrence/exposure rates for different durations since the start of the birth interval with an accuracy of one-tenth of a year. The analysis was mainly based on the accumulated occ/exp rates. The advantage of the life table method is that it is very simple. In principle it also allows an inclusion of several background variables, but in practice this easily leads to very many and small groups, and the results are difficult to interpret and summarize. These problems can be handled fairly easy by fitting multiplicative hazard models to the birth intensities.

I have used the same variables as in the life table analysis with one exception. Instead of cohorts I used a variable indicating the period for the start of the birth intervals. This is justified because it was obvious from my first studies that period was a much more important variable than year of birth. In addition to this I have also used a number of background variables. For geographical regions I used four regions, and the place of residence was further classified by type, i.e. urban or rural. As mentioned earlier, only the level of education at time of interview was known, but to get some indication of the effect of such a variable, I have used information about basic education (primary school, junior secondary school and matriculation examination). For most women this variable certainly did not change after marriage. There were no questions about social background, but to get some idea about the influence of family background I have classified the women according to the number of their own siblings. Furthermore, the sex of the children born previously was taken into account.

\section{Results}

\section{Life table analysis}

The accumulated occ/exp rates are presented in Figures I-V. For second births the original occ/exp rates are also included in two cases. The comments below are based on these figures.

In a report from the Central Statistical Office (1978) it is argued that the fertility behavior of the »baby-boom» cohorts is different compared to that of other cohorts, with a very low fertility at early ages. This was considered an important explanation for the low fertility in the beginning of the $70 \mathrm{~s}$. However, according to the figures I think a better interpretation is to say that the fertility of the »baby-boom» generation was low because this generation entered fertile age during a period of very low fertility. It is evident from the figures that the year of marriage or first birth is much more important for subsequent fertility than the year of birth.

It is difficult to locate exactly the year when the first and second birth intensities began to fall, but it seems not to have been before the late $60 \mathrm{~s}$. The development for these two parities is very much the same, but there is one important difference. For first births the decline was somewhat compensated for later on, and the proportion finally childless did not change much. However, for second births, the decline seems to be more definite. Of those women who were under the age of 25 years at first birth before the mid-60s, some 88 to 89 percent eventually experienced a second birth. The corresponding figure for those who had their first child after the late $60 \mathrm{~s}$ seems to be only about 80 percent, which is a very remarkable decline in comparison with the Scandinavian countries.

The decline of the intensities was concentrated in short birth intervals, which is quite in accordance with the trends observed in Sweden. My conclusion is that this is very much due to improvements in contraception. Thanks to more effective methods 
and the new abortion law it was possible not only to restrict the number of births, but also to better plan their timing.

According to Fougstedt (1977) the parity progression probabilities for the parities over two had fallen in succeeding cohorts at least since the one born in 1906-10. This result can also be observed here. Of those women born in 1932-36 who had their second child before the age of 25 , a good three-fourths eventually had a third child as well, but in the cohort born in 1942-46 the corresponding proportion was only one-half. As for the second child, the decline was concentrated in short intervals.

As expected we can observe a clear effect of the previous behavior on the third birth intensities. The shorter an interval between marriage and second birth the higher the propensity for a third birth. When controlling for previous behavior, age at marriage seems to be unimportant at least for women under the age of 30 at marriage.

F i g u e I. Accumulated first birth intensities in different cohorts. Duration since marriage.

a) Women under the age of 20 years at marriage

b) Women aged $20-21$ years at marriage

c) Women aged $22-24$ years at marriage

d) Women aged 25-29 years at marriage
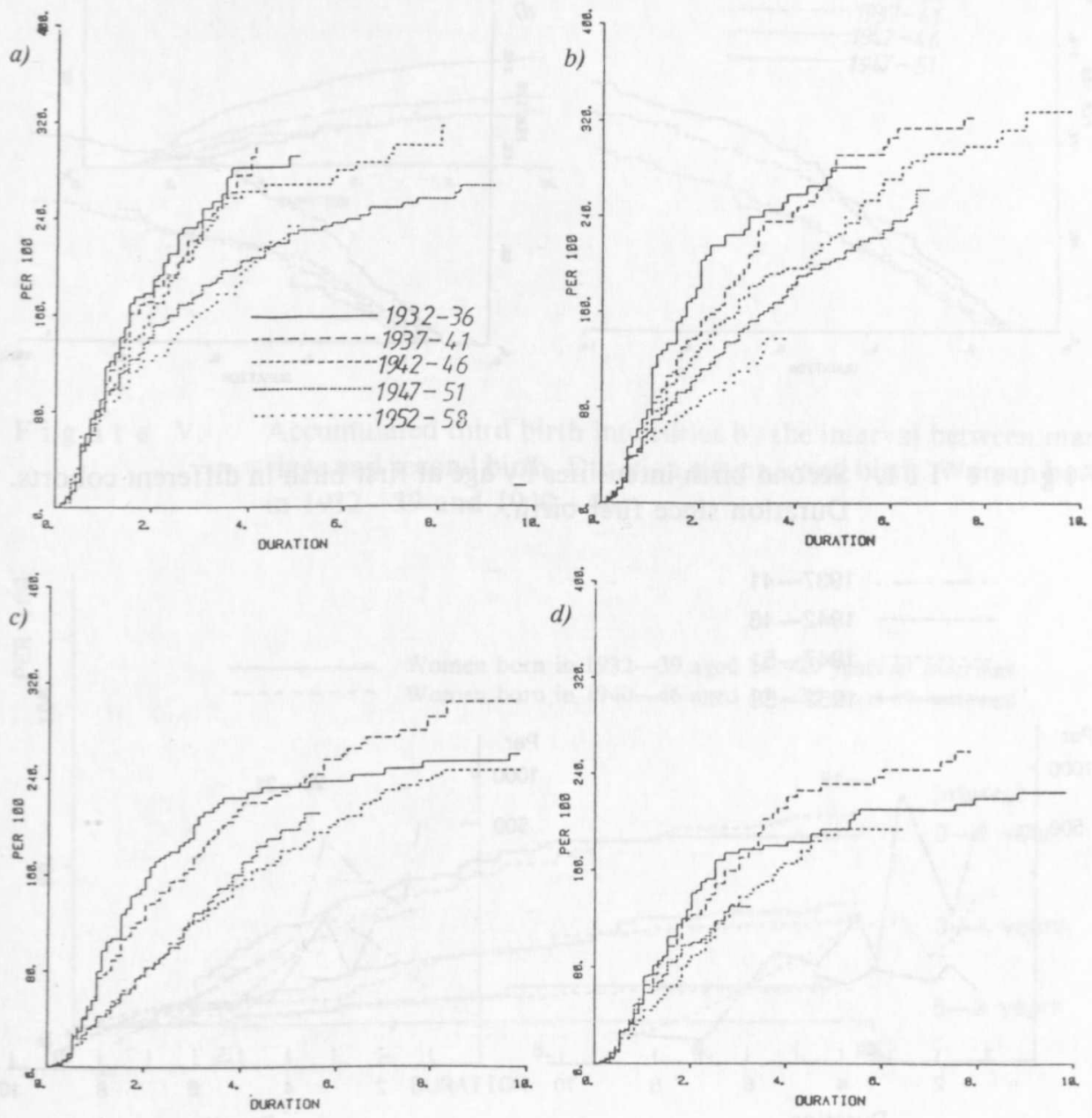
F i g u r e I I. Accumulated second birth intensities in different cohorts. Duration since first birth.

a) Women under the age of 20 years at marriage

b) Women aged $20-21$ years at marriage

c) Women aged $22-24$ years at marriage

d) Women aged 25-29 years at marriage
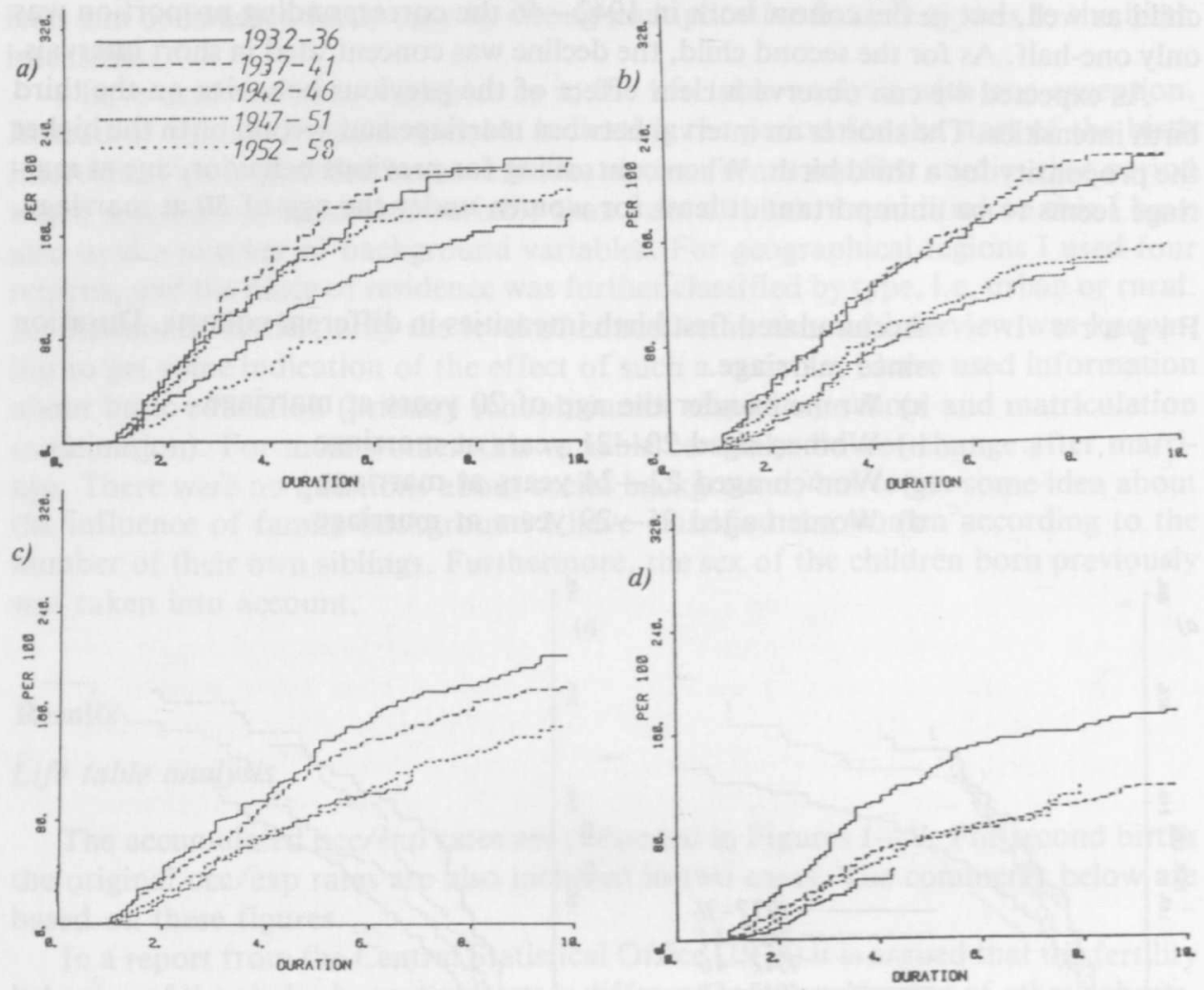

F i g u r e I I I. Second birth intensities by age at first birth in different cohorts. Duration since first birth.
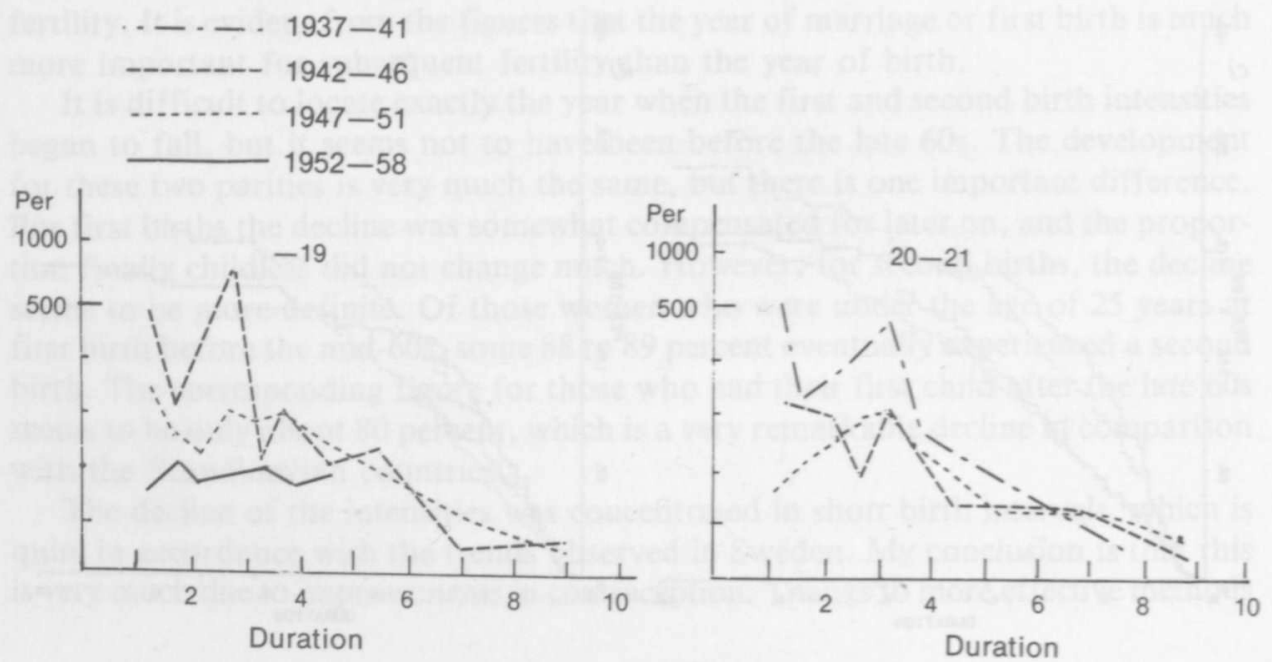
F i g u r e I V. Accumulated third birth intensities in different cohorts. Duration since second birth.

a) Women under the age of 25 years at second birth

b) Women aged $25-29$ years at second birth

c) Women aged $30-34$ years at second birth
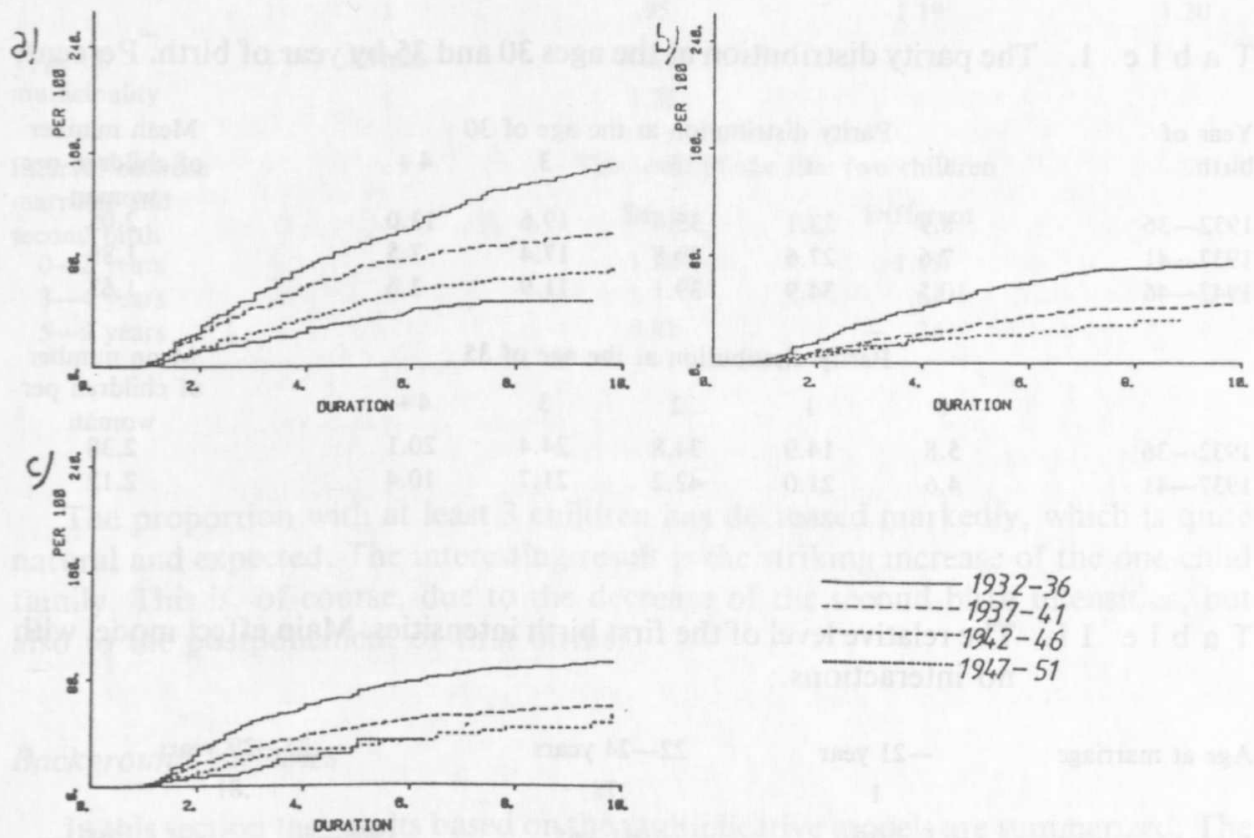

F i g u r e V. Accumulated third birth intensities by the interval between marriage and second birth. Duration since second birth. Women born in 1932-39 and 1940-46.

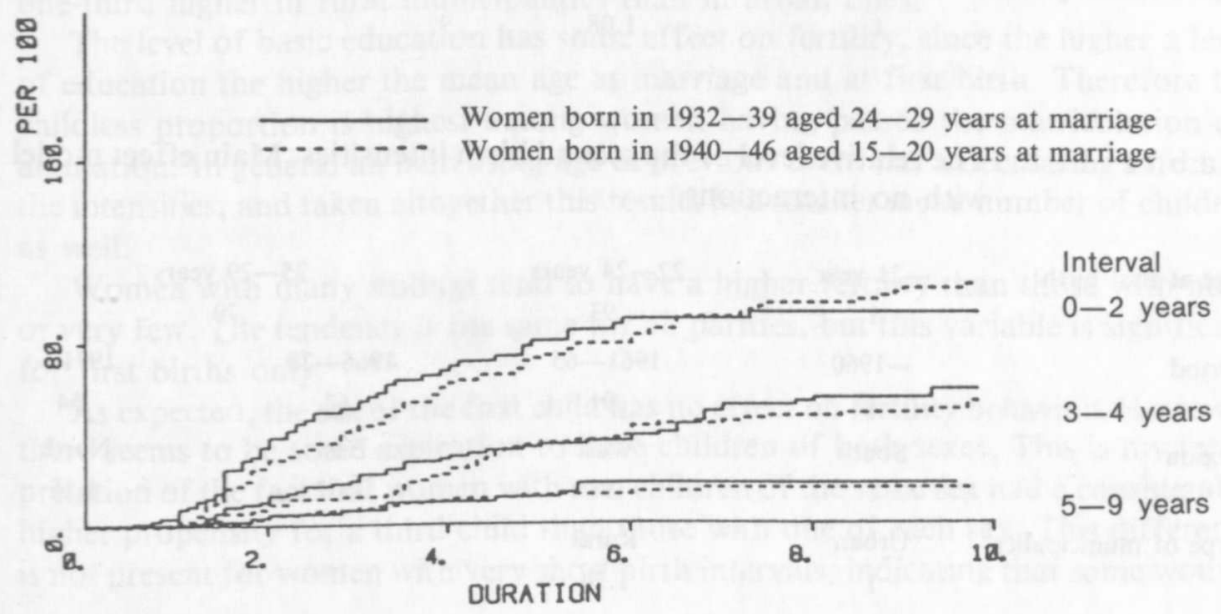


To summarize the results somewhat I have calculated the parity distributions at the age of 30 and 35 in the different cohorts. Due to the shortcomings in the observation plan the comparisons are not quite accurate, but the main trends can certainly be relied on.

$\mathrm{T}$ a b $1 \mathrm{e} 1$. The parity distribution at the ages 30 and 35 by year of birth. Percent.

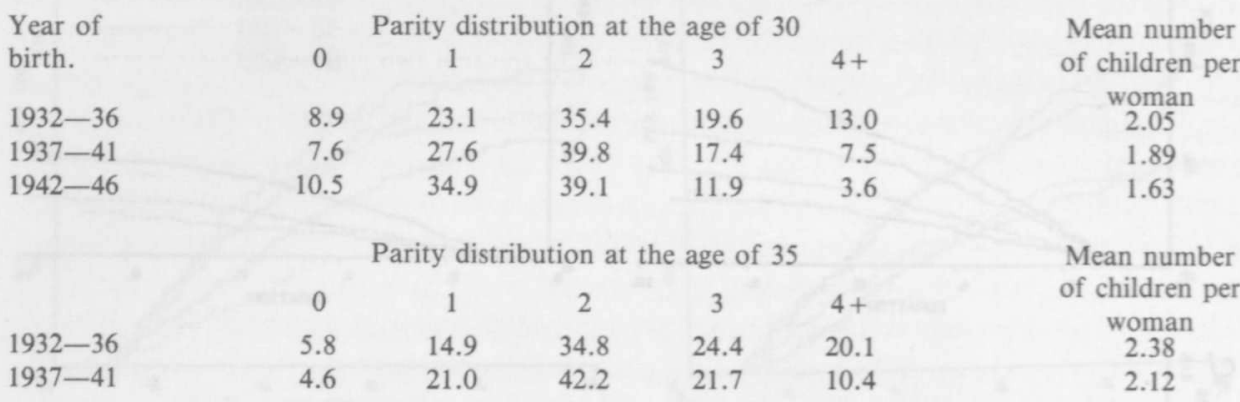

$\mathrm{T}$ a b $1 \mathrm{e}$ I I. The relative level of the first birth intensities. Main effect model with no interactions.

\begin{tabular}{lcccc} 
Age at marriage & -21 year & $22-24$ years & \multicolumn{2}{c}{$25-29$ years } \\
& 1 & .78 & $1966-70$ & .81 \\
Period & -1960 & $1961-65$ & .79 & .70 \\
& 1 & .91 & East & North \\
Region & South & West & 1.15 & 1.30 \\
& 1 & 1.13 & Matriculation & \\
Basic & Primary & Junior secondary & examination & .76 \\
education & school & school & Large & \\
& 1 & .90 & 1.24 & \\
Family size & Small & Medium & & \\
& 1 & 1.16 & &
\end{tabular}

T a b 1 e I I I. The relative level of the second birth intensities. Main effect model with no interactions.

\begin{tabular}{lcccc} 
Age at first birth & -21 year & $22-24$ years & \multicolumn{2}{c}{$25-29$ years } \\
Period & 1 & .93 & .79 & $1971-$ \\
& -1960 & $1961-65$ & $1966-70$ & .54 \\
Region & 1 & .91 & .67 & North \\
& South & West & East & 1.15 \\
Type of municipality & 1 & .98 & 1.07 & \\
& Urban & Rural & &
\end{tabular}


$\mathrm{T} \mathrm{a} \mathrm{b} \mathrm{l} \mathrm{e} \mathrm{I} \mathrm{V.} \mathrm{The} \mathrm{relative} \mathrm{level} \mathrm{of} \mathrm{the} \mathrm{third} \mathrm{birth} \mathrm{intensities.} \mathrm{Model} \mathrm{with} \mathrm{one} \mathrm{inter-}$ action.

$\begin{array}{lcccc}\text { Period } & -1960 & 1961-65 & 1966-70 & 1971- \\ & 1 & .75 & .42 & .34 \\ \text { Region } & \text { South } & \text { West } & \text { East } & \text { North } \\ & 1 & .95 & 1.19 & 1.20 \\ \text { Type of } & \text { Urban } & \text { Rural } & & \\ \text { municipality } & 1 & 1.33 & & \end{array}$

Interval between

marriage and

second birth

$0-2$ years

$3-4$ years

$5-9$ years
The sexes of the first two children

$\begin{array}{lc}\text { Same } & \text { Different } \\ 1.14 & 1.15 \\ 1 & .63 \\ 0.42 & .34\end{array}$

The proportion with at least 3 children has decreased markedly, which is quite natural and expected. The interesting result is the striking increase of the one-child family. This is, of course, due to the decrease of the second birth intensities, but also to the postponement of first births.

\section{Background variables}

In this section the results based on the multiplicative models are summarized. The relative levels of the intensities are presented in Tables II to IV. With one exception no interactions are included in the models presented here.

The regional differences already known, low fertility in the south and the west and a higher level in the east and the north, are apparent for all parities. However, for the second birth the differences are negligible. This reflects the fact that, inspite of the decline observed above, the two-child family is such an ordinary ideal, that of all the other background variables, only one had any significant effect on the intensities. The only exception is type of municipality, the importance of which increases from parity to parity. For third births the level of the intensities was about one-third higher in rural municipalities than in urban ones.

The level of basic education has some effect on fertility, since the higher a level of education the higher the mean age at marriage and at first birth. Therefore the childless proportion is highest among women having passed the matriculation examination. In general an increasing age at previous event has a decreasing effect on the intensities, and taken altogether this results in a smaller mean number of children as well.

Women with many siblings tend to have a higher fertility than those with none or very few. The tendency is the same for all parities, but this variable is significant for first births only.

As expected, the sex of the first child has no effect on fertility behavior. However, there seems to be some aspiration to have children of both sexes. This is my interpretation of the fact that women with two children of the same sex had a considerably higher propensity for a third child than those with one of each sex. This difference is not present for women with very short birth intervals, indicating that some women 
are highly fertile and they have many children with short intervals irrespective of their sexes.

\section{References}

Brunborg, Helge; and Kravdal, Øystein. (1986). Barnetall blant norske kvinner. En paritetsanalyse på grunnlag av registerdata. Fertility by Birth Order in Norway. A Register Based Analysis. Rapporter 86/27. Oslo-Kongsvinger: Statistisk sentralbyrå.

Central Statistical Office of Finland. (1978). Review of Vital Statistics 1961-1975. OSF VI A: 139.

Finnäs, Fjalar; and Hoem,. Jan M. (1979). Cohort trends in cohabitational birth intervals in Denmark, 1975. In: The Fifth Scandinavian Demographic Symposium. 13-16 June 1979 at Hurdalssjøen, Norway. Scandinavian Population Studies 5, edited by Helge Brunborg and Knut Sørensen, pp. 196-210. Oslo: Scandinavian Demographic Society.

Finnäs, Fjalar; and Hoem, Jan M. (1980). Starting age and subsequent birth intervals in cohabitational unions on current Danish cohorts, 1975. Demography (USA) 17 (3): 275-296.

Fougstedt, Gunnar. (1977). Trends and Factors of Fertility in Finland. Commentationes Scientiarium Socialium 7. Helsinki, Finland: Societas Scientiarum Fennica.

Johansson, Leif; and Finnäs, Fjalar (1983). Fertility of Swedish women born 1927-1960. Urval no. 14. Stockholm, Sweden: Statistiska centralbyrån.

Riihinen, Olavi; Pulkkinen, Aimo; and Ritamies, Marketta. (1980). Suomalaisen perheen lapsiluku. (Number of children in the Finnish family). Väestöntutkimuslaitoksen julkaisusarja D, n:o 7. Helsinki, Finland: Väestöntutkimuslaitos.

Sievers, Kai; Koskelainen, Osmo; and Leppo, Kimmo. (1974). Suomalaisten sukupuolielämä. (Sexual life of the Finns). Porvoo-Helsinki: WSOY.

Stockholm Research Reports in Demography. (1984-87). Stockholm, Sweden: University of Stockholm, Section of Demography. (SUDA) 